Çukurova Üniversitesi Mühendislik Mimarlık Fakültesi Dergisi, 35(1), ss. 159-171, Mart 2020

Çukurova University Journal of the Faculty of Engineering and Architecture, 35(1), pp. 159-171, March 2020

\title{
Elektrodepolanmış Nanokompozit Kaplamalarda Elektrolit Bileşenlerinin Etkisi
}

\author{
Ersin ÜNAL ${ }^{1}$, Abdulkadir YAŞAR ${ }^{* 2}$, İsmail Hakkı KARAHAN ${ }^{3}$ \\ ${ }^{1}$ Osmaniye Korkut Ata Üniversitesi, Mühendislik Fakültesi, Makine Mühendisliği Bölümü, Osmaniye \\ ${ }^{2}$ Çukurova Üniversitesi, Ceyhan Mühendislik Fakültesi, Makine Mühendisliği Bölümü, Adana \\ ${ }^{3}$ Mustafa Kemal Üniversitesi, Fen Edebiyat Fakültesi, Fizik Bölümü, Hatay
}

Geliş tarihi: 04.02.2020 Kabul tarihi: 15.05 .2020

\section{$\ddot{O} z$}

$\mathrm{Bu}$ çalışmada, nikel esaslı alaşım ve nanokompozit kaplamalar elektrokimyasal depolama metodu ile paslanmaz çelik altlık üzerine üretilmiştir. Watts tipi nikel banyosuna bor kaynağı olarak trimetilamin boran (TMAB) ilave edilerek Ni-B alaşım kaplama elde edilmiş, daha sonra buna ilave olarak banyoya titanyum diborür $\left(\mathrm{TiB}_{2}\right)$ seramik nano parçacıkları ilave edilerek nanokompozit kaplama elde edilmiştir. Elektrolit bileşenlerinin kaplama özelliklerine etkilerini incelemek amaciyla elektrokimyasal, mikrosertlik, korozyon dayanımı ve yüzey morfolojileri açısından analizler yapılmıştır. Yapılan incelemeler sonucunda her banyo bileşeninin morfoloji, sertlik ve korozyon dayanımı gibi özellikleri ciddi miktarda etkilediği görülmektedir. Genel olarak yüzey morfolojiler pürüzsüz olmakla birlikte, nanokompozit kaplamanın yüzeyinin daha kaba olduğu optik resimlerden anlaşılmaktadır. Ana yapıya bor elementi ilavesi mikro sertliği yaklaşı \%38 oranında artırırken, $\mathrm{TiB}_{2}$ takviyesiyle birlikte saf nikele göre \%140, Ni-B alaşımına göre \%75 oranında iyileşme olmasına sebep olmuştur. Bor takviyesi korozyon dayanımını azaltırken, $\mathrm{TiB}_{2}$ takviyesi korozyon dayanımında artışa neden olmuştur.

Anahtar Kelimeler:Elektrodepolama, Nanokompozit kaplamalar, Ni-B alaşım, Elektrokimyasal kaplama

Effect of Electrolyte Components on Electrodeposited Nanocomposite Coatings

\begin{abstract}
In this study, nickel-based alloy and nanocomposite coatings were produced on a stainless steel base with the electrochemical deposition method. Ni-B alloy coating was obtained by adding trimethylamine borane (TMAB) as a boron source to the Watts type nickel bath, and in addition, titanium diboride $\left(\mathrm{TiB}_{2}\right)$ ceramic nanoparticles were added to the bath in order to obtain a nanocomposite coating. In order to examine the effects of electrolyte components on coating properties, analyzes were carried out in terms of electrochemical, microhardness, corrosion resistance and surface morphology. As a result of the examinations, it was seen that each bath component has a serious effect on the coating properties such as morphology, hardness and corrosion resistance. In general, although surface morphologies were smooth, it was understood from the optical images that the surface of the nanocomposite coating was more coarser. While the addition of boron element to the main structure increased the microhardness by about $38 \%$, with the $\mathrm{TiB}_{2}$ supplement, it caused $140 \%$ improvement over pure nickel and 75\% improvement over Ni-B alloy. While boron reinforcement reduced corrosion resistance, $\mathrm{TiB}_{2}$ reinforcement caused an increase in corrosion resistance.
\end{abstract}

Keywords: Electrodeposition, Nanocomposite coatings, Ni-B alloys, Electrochemical coatings

*Sorumlu (Corresponding author) yazar: Abdulkadir YAŞAR, ayasar@cu.edu.tr 


\section{GíRiş̧}

Mühendislik ve endüstriyel alanlarda kullanılan malzemeler zorlu hizmet koşulları ile karşı karşıya kalmakta ve bu koşullar altında aşınma ve korozyona dayanıklı olmaları beklenmektedir. Korozyon ve aşınma nedenli ortaya çıkan kesinti ve fabrika duruşları sebebiyle her yıl milyarlarca liralık maliyet ortaya çıkmaktadır [1]. Bir malzemenin, genellikle korozyon, aşınma ve kırık şeklindeki hasarı, yüzeyinden başlar ve bu da performansını ve hizmet ömrünü azaltabilir [2-4]. Bunun başlıca nedeni, yüzeyin genellikle ilk olarak zararlı etkilere maruz kalmasıdır. Malzemelerin tümünün özelliklerinin iyileştirilmesiyle karşılaştırıldığında, yüzey teknolojisi (kaplama ve modifikasyon) etkili ve düşük maliyetli bir yöntemdir. Bu nedenle, yüzey modifikasyonu veya yüzey kaplama teknolojisi, özellikle korozyon ve aşınma sürecini önlemek ve mühendislik parçalarının bozulma sürecini geciktirmek için üretim sürecinde yaygın olarak kullanılmaktadır $[5,6]$. Malzemelerin yüzey dayanımı özellikleri nitrürleme, karbonitrürleme, indüksiyonla sertleştirme, fiziksel ve kimyasal buhar biriktirme, karbürleme, lazerle sertleştirme, alevle sertleştirme, iç oksidasyon, elektriksiz veya elektrokimyasal depolama gibi birçok teknikle iyileştirilebilir [6]. Elektrikli ve elektriksiz depolama teknikleri kendi içinde karşılaştırıldıklarında, yüksek sıcaklık ve yüksek pH gereksinimlerinden dolayı elektriksiz depolama tekniği dezavantajlı duruma düşmektedir. Buna karşın elektrikli depolama işlemi hem düşük sıcaklık hem de düşük $\mathrm{pH}$ değerlerinde gerçekleştirilebilmektedir. Elektrokimyasal depolama elektrik akımı iletebilen bir altlık üzerine yine elektrik akımı iletebilen metal ya da alaşımların yoğun ve altlığa sıkı tutunmuş bir şekilde kaplanabildiği ekonomik ve etkili bir yüzey modifikasyon tekniğidir. Fakat teknolojinin ilerlemesi ile birlikte metal veya alaşımların performansı bazı uygulamalarda yeterli olamamaktadır. Metal veya alaşımların dayanımını daha üst seviyelere ulaștırmak için seramik parçacıklarla takviye edilmesi gerekmektedir ve elektrodepolama tekniği kompozit kaplamaların üretilebilmesi için çok uygun bir tekniktir [7].
Elektrokimyasal olarak biriktirilen metal ya da alaşım tabakaların içine çözünmeyen ikinci faz parçacıkların eşdepolanması ile elde edilen kompozit kaplamaların üretilmesinde kullanılan bu yöntem yaygın bir şekilde kullanılmaktadır [8]. Bu teknikte karbürler, nitrürler, oksitler ve borürler gibi birçok seramik takviye parçacık çeşidi başarıyla eşdepolanabilmektedir [9]. Metal ve alaşım kaplamaların ikinci faz parçacıklarla takviyesiyle sadece sürtünme, aşınma, sertlik ve aşınma direnci gibi özellikler değil aynı zamanda korozyon direnci ve kimyasal özelliklerinde de gelişme sağlanmaktadır [10].

Son yıllarda elektrodepolanmış nanokompozit kaplamalarla ilgili araştırmalarda anayapı malzemesi olarak siklıkla tercih edilen nikel-bor alaşım kaplamalar yüksek sertlik, yüksek aşınma direnci (sert krom kaplamalardan daha iyi) ve iyi anti korozyon özelliklerine sahiptir. Ni-B kaplamalar otomotiv, uzay, nükleer, petrokimya, bilgisayar, elektronik, plastik, optik, tekstil, kâğıt, gıda ve matbaa endüstrilerinde kullanılmaktadır [11,12]. Ni-B alaşımının elektrodepolama metoduyla takviye edildiği yayınlardan bazılarına hBN [1, 13-16], $\mathrm{Al}_{2} \mathrm{O}_{3}$ [2,5], YSZ [3], $\mathrm{CeO}_{2}$ [6], $\mathrm{TiC}$ [17], WC [18], $\mathrm{SiC}$ [19-21], $\mathrm{Si}_{3} \mathrm{~N}_{4}$ [22], elmas $[23,24], \mathrm{Y}_{2} \mathrm{O}_{3}$ [25], $\mathrm{Fe}_{2} \mathrm{O}_{3}$ [26], AlN [27], $\mathrm{Tl}_{2} \mathrm{O}_{3}$ [28] örnek olarak verilebilir.

Titanyum diborür $\left(\mathrm{TiB}_{2}\right)$ yüksek sertlik $(3350 \mathrm{Hv})$, yüksek erime noktası (2980 ), düşük elektrik direnci $(9 \Omega \mathrm{cm})$, yüksek 1slanabilirlik, iyi korozyon direnci, iyi ısıl şok direnci ve kimyasal olarak asal olma gibi özelliklere sahiptir. Ayrıca, $\mathrm{TiB}_{2}$ mükemmel mekanik ve aşınma direnci özellikleriyle de bilinmektedir. $\mathrm{Bu}$ özellikleri nedeniyle türbin kanatları, yanma odaları, kimyasal reaktör kapları, elektrotlar, potalar, pompa çarkları ve kesici takımlar gibi birçok yüzey mühendisliği uygulamalarında uygun bir kaplama malzemesidir [29-31]. Gyawali ve arkadaşları [31], Ni-W/TiB 2 kompozit kaplamasını elektrodepolama tekniği ile üretmişler, mekanik, sürtünme, aşınma ve yağlanma özelliklerini incelemişlerdir. Yazarlar bu kompozit kaplamanın hem kuru hem de yağlı şartlar altında, saf nikel ve $\mathrm{Ni}-\mathrm{W}$ alaşım kaplamaya göre daha gelişmiş sürtünme ve aşınma özellikleri sergilediğini 
raporlamışlardır. Yazarlar ayrıca kompozit kaplamanın mikro sertliğinin ve çizilme mukavemetinin de saf nikel ve Ni-W alaşım kaplamaya göre daha yüksek olduğunu belirtmişlerdir. Xiaozhen ve arkadaşları [32], $\mathrm{TiB}_{2}$ ve $\mathrm{Sm}_{2} \mathrm{O}_{3}$ parçacıklarının karışımıyla takviye ettikleri Ni alaşımlı kompozit kaplamayı çelik altlık üzerine elektro kimyasal olarak depolamışlardır. Yazarlar karşılaştırmayı saf nikel, $\mathrm{Ni}-\mathrm{TiB}_{2}, \mathrm{Ni}-\mathrm{Sm}_{2} \mathrm{O}_{3}$ elektrokimyasal kaplamalarla yapmışlar ve $\mathrm{Ni}-\mathrm{TiB}_{2}-\mathrm{Sm}_{2} \mathrm{O}_{3}$ kompozit kaplamanın mikro sertliğinin diğer kaplamalardan daha yüksek olduğunu, ayrıca aşınma ağırlık kaybının ise daha düşük olduğunu raporlamışlardır. Yazarlar sürtünme katsayısında ise en düşük değerin $\mathrm{Ni}-\mathrm{Sm}_{2} \mathrm{O}_{3}$ kompozit kaplamasına ait olduğunu belirtmişlerdir. Xiaozhen ve arkadaşları [33], $\mathrm{TiB}_{2}$ ve $\mathrm{Dy}_{2} \mathrm{O}_{3}$ parçacıklarının karışımından oluşan takviye fazı ile destekledikleri nikel matrisini elektrodepolama metodu ile çelik altlık üzerine kaplamışlar ve ürettikleri kompozit malzemenin sürtünme ve aşınma özelliklerini incelemişlerdir. Yazarlar karşılaştırma amacıyla saf nikel ve $\mathrm{Ni}^{-\mathrm{TiB}_{2}}$ kaplamalarını kullanmışlardır. Yazarların elde ettikleri sonuçlara göre en düşük sürtünme katsayısı ve aşınma ağırlık kaybı ve en yüksek mikro sertlik değerleri $\mathrm{Ni}-\mathrm{TiB}_{2}-\mathrm{Dy}_{2} \mathrm{O}_{3}$ kompozit kaplamasında elde edilmiştir. Gyawali ve arkadaşları [30], saf nikel metalini $\mathrm{TiB}_{2}$ parçacıkları ile takviye ederek darbeli elektrokaplama tekniği ile paslanmaz çelik üzerine depolamışlardır. Farklı $\mathrm{TiB}_{2}$ banyo parçacık konsantrasyonlarında numuneler üretmişler ve mikrosertlik, korozyon dayanımı gibi özellikleri incelemişlerdir. $\mathrm{TiB}_{2}$ takviyesiyle kompozit kaplamanın mikrosertlik değeri saf nikel kaplamaya göre 3 kat daha fazla artış göstermiştir. Ayrıca $\mathrm{TiB}_{2}$ takviyesinin saf nikele korozyon dayanımında iyileşme sağladığını raporlamışlardır.

$\mathrm{Bu}$ çalışmada nikel metalinin depolandığı Watts tipi elektrolite önce bor elementi kaynağı olan TMAB eklenmiş, daha sonra $\mathrm{TiB}_{2}$ ikinci faz seramik parçacıkları ilave edilmiş ve böylece nikel ana yapısı önce bor elementi ile daha sonra $\mathrm{TiB}_{2}$ parçacıkları ile takviye edilmiştir. Mükemmel mekanik özellikleri ile bilinen $\mathrm{Ni}$-B ve $\mathrm{TiB}_{2}$ ikilisini ilk kez bir arada kullanarak hem literatüre hem de sanayiye önemli bir alternatif sunulmas1 amaçlanmaktadır. $\mathrm{Bu}$ takviyelerin hem Ni-B alaşım kaplamayı hem de $\mathrm{Ni}-\mathrm{B} / \mathrm{TiB}_{2}$ nanokompozit kaplamayı nasıl etkilediği elektrokimyasal, morfolojik, mikrosertlik ve korozyon dayanımı gibi analiz metotları ile incelenmiştir.

\section{MATERYAL VE METOT}

Saf nikel, titanyum diborür $\left(\mathrm{TiB}_{2}\right)$ takviyeli nanokompozit kaplamalar ve Ni-B alaşım kaplamalar paslanmaz çelik altlık üzerine, Watts tipi nikel banyosunda elektro-kimyasal kaplama metodu ile depolanmıştır. Bütün elektrokimyasal deneyler $\mathrm{CH}$ Instruments 608E model elektrokimyasal analiz cihazıyla gerçekleştirilmiş ve geleneksel üç elektrotlu sistem kullanılmıştır. Anot olarak platin tel, katot olarak ise $4 \mathrm{~cm}^{2}$ alana sahip paslanmaz çelik plaka kullanılmıştır. Referans elektrot olarak ise doygun kalomel elektrot (SCE) kullanılmıştır. Anot ve katot kaplama banyosu içinde dikey ve birbirine paralel olarak yerleştirilmiştir ve aralarında yaklaşık $3 \mathrm{~cm}$ mesafe bırakılmıştır. Paslanmaz çelik altlık depolama işlemine tabi tutulmadan önce kalından inceye doğru zımpara kağıtları ile zımparalanmış ve daha sonra \%10 oranında hidroklorik $(\mathrm{HCl})$ asitle karıştırılmış saf su içinde dağlanmış ve daha sonra saf su ile durulanarak oda sicaklığında kurutulmuştur. Bütün kimyasal maddeler SigmaAldrich firmasının ürünleridir ve saflık dereceleri Çizelge 1'de ilgili kimyasalın yanında verilmiştir. Dönüşümlü voltametri (CV) deneyleri için kullanılan altlık, bu deneyden sonra tekrar aynı işlemden geçirilerek kullanılmıştır. Banyo bileşenleri ve depolama şartları Çizelge 1'de verilmiştir. Sheu ve arkadaşları [34] Ni-B ile ilgili çalışmalarında elektrokimyasal depolamada bor kaynağı olarak kullanılabilen dimetilamin boran'ın (DMAB), trimetilamin boran kompleksi'ne (TMAB) göre daha yüksek sicaklıklarda $\left(>75^{\circ} \mathrm{C}\right)$ çözündüğünü ve TMAB'lı kaplama banyosunun diğerine göre daha stabil olduğunu belirtmişlerdir. $\mathrm{Bu}$ açıklamalar 1şı̆̆ında bor kaynağı olarak (TMAB) tercih edilmiştir. Sodyum dodesil sülfat (SDS) ve sakarin gibi katkılar kompozit kaplama üretilirken titanyum diborür parçacıklarının elektrolit içinde süspanse edilebilmesi ve 
topaklanmaları önlemek için kullanılmıştır. Ayrıca nanokompozit kaplama banyosu depolama öncesinde Hielscher UP 200S marka ve model ultrasonik karıştırma cihazı ile $30 \mathrm{dk}$ boyunca karıştırılmıştır. Bu işlem yapılırken çevrim değeri 1 olarak, genlik değeri ise $\% 70$ olarak ayarlanmıştır $(\sim 20 \mathrm{kHz})$. Banyoya nano boyutta takviye seramik parçacıklar eklenmesi ile birlikte ortaya çıkan topaklanmaların önlenebilmesi için mutlaka ultrasonik karıştırma işleminin uygulanması gerekmektedir. Ünal ve Karahan [14], depolama öncesi ultrasonik karıştırmanın etkisini araştırmışlar ve bu işlemin hem parçacık topaklanmasını önleme açısından hem de parçacıkların homojen dağılımı açısından çok etkili olduğunu raporlamışlardır. Titanyum diborür parçacıklarının ortalama toz boyutu $500 \mathrm{~nm}$ 'dir (satın alınan firmanın bildirdiği toz boyutu). $\mathrm{TiB}_{2}$ nano parçacıklar Nanografi firmasından satın alınmıştır ve \%99 saflıktadır. Kaplama depolanma süresi $60 \mathrm{dk}$ olarak ayarlanmıştır ve depolama boyunca sicaklık $43 \pm 1{ }^{\circ} \mathrm{C}$ 'de tutulmuştur. Ayrica depolama esnasında banyo manyetik karıştırıcı ile karıştırılmıştır. Banyonun $\mathrm{pH}$ değeri $\mathrm{HCl}$ asit ve sodyum hidroksit $(\mathrm{NaOH})$ kullanılarak 4 değerine ayarlanmıştır. Bütün depolama işlemlerinde akım yoğunluğu değeri sabit tutulmuş ve $50 \mathrm{~mA} / \mathrm{cm}^{2}$ olarak uygulanmıştır. Depolama sonrası kaplamalar saf su ile durulanmış ve oda sıcaklığında kurumaya bırakılmıştır. Mikro sertlik ölçümleri Future-TECH FM-700e marka ve model cihaz kullanılarak gerçekleştirilmiştir. Mikro sertlik değerleri ölçülürken $500 \mathrm{~g}$ yük numune üzerine $10 \mathrm{~s}$ boyunca uygulanmıştır. Her bir numunede en az 10 farklı bölgeden ölçümler alınmış ve bu ölçümlerin ortalaması mikro sertlik değeri olarak kabul edilmiştir. Yapılan mikro sertlik ölçümleri neticesinde ortalamadan aşırı derecede sapan sertlik değerleri numunenin genel ortalamasına dahil edilmemiştir. Kaplamaların korozyon performanslarının değerlendirildiği açık devre potansiyeli (OCP) grafikleri kütlece \%3,5 $\mathrm{NaCl}$ çözeltisinde $3600 \mathrm{~s}$ boyunca ölçüm alınarak gerçekleştirilmiştir. Nano $\mathrm{TiB}_{2}$ parçacıkların toz boyutu ölçümü verileri Malvern Mastersizer 3000 marka ve model cihaz kullanilarak elde edilmiştir. Optik mikroskop çekimleri ise Olympus BX51 marka ve model cihaz kullanılarak gerçekleştirilmiştir. CV deneylerinde tarama hızı $10 \mathrm{mV} / \mathrm{s}$ olarak ayarlanmıştır ve tarama -1,2 V ile 1,2 V arasındaki potansiyel değerlerinde gerçekleştirilmiştir. $\mathrm{Bu}$ potansiyeller Watts tipi nikel banyosunun tipik özelliklerine göre seçilmiştir.

Çizelge 1. Elektrolit bileşenleri ve üretim parametreleri

\begin{tabular}{|l|l|}
\hline \multicolumn{2}{|l|}{ Elektrolit bileşenleri ve saflık dereceleri/ Üretim Parametreleri } \\
\hline $\mathrm{NiSO}_{4} \cdot 6 \mathrm{H}_{2} \mathrm{O}$ (Nikel sülfat hekza hidrat) $\% 99,99$ & $240 \mathrm{~g} / 1$ \\
\hline $\mathrm{NiCl}_{2} \cdot 6 \mathrm{H}_{2} \mathrm{O}$ (Nikel klorür hekza hidrat) $\% 98$ & $45 \mathrm{~g} / 1$ \\
\hline $\mathrm{H}_{3} \mathrm{BO}_{3}$ (Borik asit) $\% 99,5$ & $30 \mathrm{~g} / 1$ \\
\hline Trimetilamin boran kompleks (TMAB) $\% 97$ & $3 \mathrm{~g} / 1$ \\
\hline Titanyum diborür tozu (TiB 2 ) $\% 99$ & $9 \mathrm{~g} / 1$ \\
\hline Sodyum dodesil sülfat (SDS) $\% 99$ & $0,5 \mathrm{~g} / 1$ \\
\hline Sakarin \%98 & $2 \mathrm{~g} / 1$ \\
\hline Akım yoğunluğu & $50 \mathrm{~mA} / \mathrm{cm}^{2}$ \\
\hline pH & 4 \\
\hline Sicaklık & $43 \pm 1^{\circ} \mathrm{C}$ \\
\hline Süre & $60 \mathrm{dk}$ \\
\hline Banyo karıştırma hızı & $200-300 \mathrm{rpm}$ \\
\hline Depolama öncesi ultrasonik karıştırma & $30 \mathrm{dk}$ \\
\hline
\end{tabular}

\section{BULGULAR VE TARTIŞMA}

Şekil 1'de nano $\mathrm{TiB}_{2}$ tozlarının parçacık boyutu ölçüm cihazı ile elde edilen değerler verilmiştir.
Elde edilen değerlere göre, tozların \%50 kadar miktarı $1 \mu$ m'un altında toz boyutuna sahiptir. Geriye kalan tozların boyutu ise $1 \mu \mathrm{m}$ 'dan büyük görünmektedir. Mikron boyutunda çıkan tozların 
büyük bir çoğunluğunun topaklanma sonucu oluştuğu düşünülmektedir. Elektrodepolama öncesi $30 \mathrm{dk}$ banyonun ultrasonik olarak karıştırılması işlemi bu topaklanmaları gidermek için yapılmaktadır. Öılçüm sonuçları incelendiğinde en büyük parçacık boyutu $4 \mu \mathrm{m}$ 'dan küçüktür. En küçük parçacık boyutu ise yaklaşık $200 \mathrm{~nm}$ civarındadır.

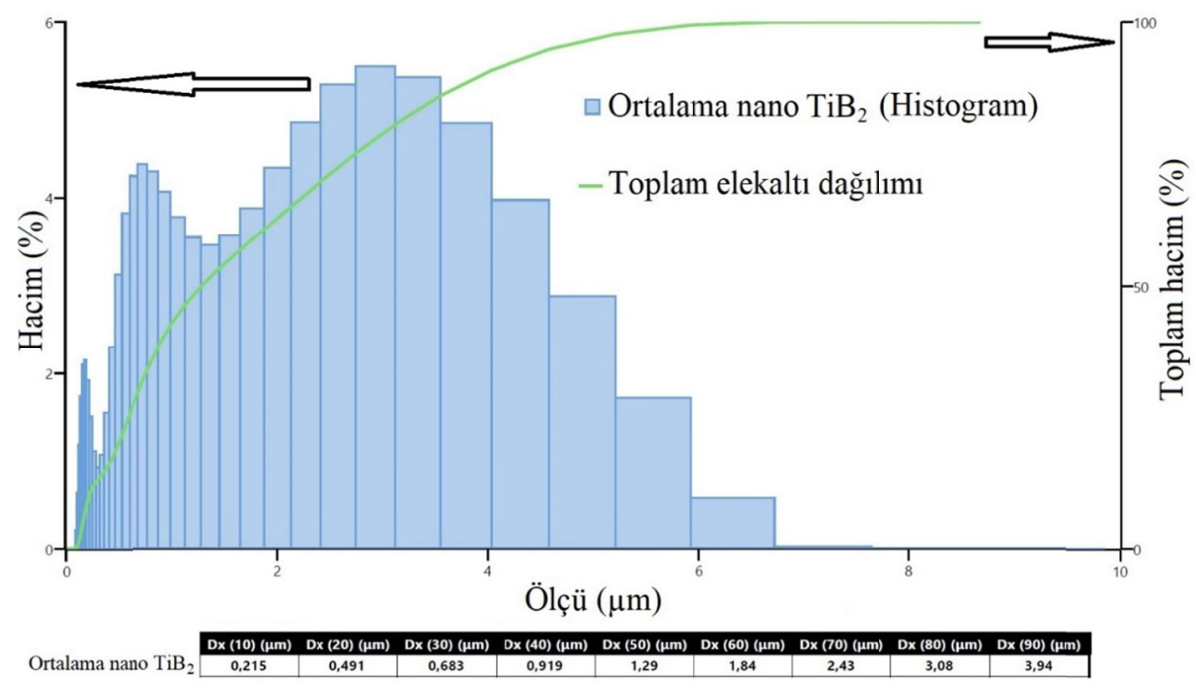

Şekil 1. Nano $\mathrm{TiB}_{2}$ parçacıkların toz boyutu dağılımı

Şekil 2'de saf nikel, Ni-B alaşım ve $\mathrm{Ni}-\mathrm{B} / \mathrm{TiB}_{2}$ nanokompozit kaplamaların kronopotansiyometri grafikleri verilmiştir. $\mathrm{Bu}$ grafikler potansiyel değişiminin sabit akım uygulanması durumunda zamanın fonksiyonu olarak elde edildiği eğrilerdir [35]. Bu grafikler sayesinde belirlenen sabit bir akımda depolama esnasında potansiyelin hangi değerlerde gerçekleştiği ve değişen zamanla birlikte ne tür değişimler gerçekleştirdiği gözlemlenebilir. Stabil banyolarda bu eğriler daha yatay bir seyir izlemekte ve ani voltaj değişimleri görülmemektedir, fakat elektrolite eklenen her bileşenle birlikte ani voltaj azalma ve yükselmelerinin olduğu salınımlı bir eğri yapısı ortaya çıkabilmektedir. Şekil 2 incelendiğinde saf nikelin depolandığı Watts tipi nikel banyosunun nispeten stabil olduğu söylenebilir. Banyoya bor kaynağı olarak kullanılan TMAB'ın eklenmesi depolanma potansiyellerinde ani salınımların ortaya çıkmasına sebep olmuştur. $\mathrm{Bu}$ salınımlar Ni-B alaşım kaplamanın dengesiz bir şekilde depolandığının bir göstergesi olabilir, zaten elde edilen Ni-B alaşım filmi de iç gerginlikten dolayı altlık yüzeyine tutunamamakta ve kıvrılarak altlıktan ayrılmaktadır. Nikel kafes yapısına bor atomları katı çözelti sertleşmesine sebep olacak şekilde yerleşmekte ve aşırı kırılgan ve gergin bir yap1 ortaya çıkmaktadır [34]. Nanokompozit Ni-B$\mathrm{TiB}_{2}$ kaplamanın kronopotansiyometri grafiği incelendiğinde nispeten stabill bir seyir izlediği söylenebilir. Bu duruma nanokompozit kaplama banyosuna eklenen SDS ve sakarin gibi katk1 maddelerinin olumlu bir etkisinin olduğu söylenebilir. Saf nikel ve nanokompozit kaplamaların paslanmaz çelik altlık malzemesine adhezyonu Ni-B alaşım kaplamaya göre çok daha iyi elde edilmiştir. Literatürde Ni-B alaşım kaplamaların mikro çatlaklı olduğu ve aşırı kırılgan olduğu raporlanmaktadır [36]. Bu konu ile alakalı bazı çalışmalarda, bu sorunun çözümü için bor içeriğinin düşük tutulması gerektiği, diğer bir alternatif ise bor kaynağının banyoya aralıklı bir şekilde ilave edilmesi gerektiği ifade edilmiştir [37,38]. Grafikten de görüldüğü üzere banyoya TMAB ve $\mathrm{TiB}_{2}$ parçacıkları ilavesiyle birlikte sabit akım değerini sağlayabilmek için elektrolitin depolanma potansiyelinin bir miktar artış gösterdiği anlaşılmaktadır. Banyoya bileşenlerin eklenmesi ile birlikte depolanma voltaj1 -1,3 V'tan $-1,36 \mathrm{~V}$ civarlarına yükselmiştir. 


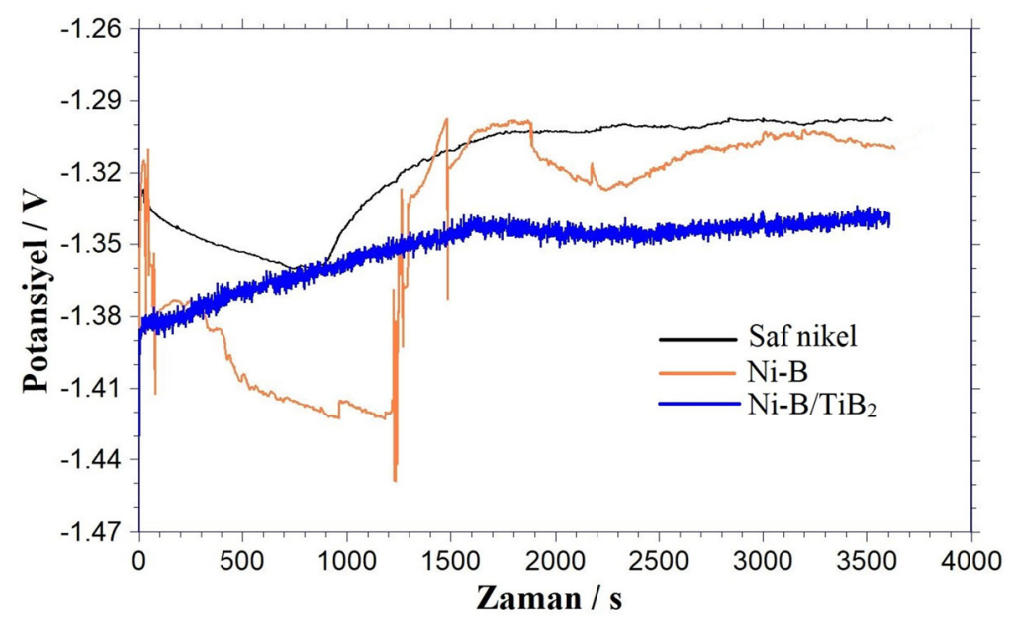

Şekil 2. Saf nikel, Ni-B alaşım ve Ni-B/TiB 2 nanokompozit kaplamaların kronopotansiyometri grafikleri

Şekil 3'te saf nikel, Ni-B alaşım ve $\mathrm{Ni}-\mathrm{B} / \mathrm{TiB}_{2}$ nanokompozit kaplamaların optik mikroskop resimleri $1000 \mathrm{x}$ ve $500 \mathrm{x}$ büyütme değerinde karşılaştırmalı olarak sunulmuștur. Genel olarak kaplamaların yüzey morfolojilerinin pürüzsüz olduğu söylenebilir. Ama Ni-B alaşım kaplama diğerlerine göre düz bir görüntü sergilemektedir. $\mathrm{Ni}-\mathrm{B} / \mathrm{TiB}_{2}$ nanokompozit kaplama ise diğerlerine göre en pürüzlü morfolojiye sahiptir. Bu duruma $\mathrm{TiB}_{2}$ seramik parçacıklarının sebep olduğu söylenebilir. Guglielmi [39] çalışmasında elektrik akımıla depolanabilen metal iyonlarıyla birlikte nano veya mikro boyuttaki seramik parçacıkların birlikte depolanması ve parçacıkların ana yapıya dahil olması olayını şu şekilde izah etmiştir. Önce iyonlar elektrolit içindeki seramik parçacıkların yüzeyine adsorblanmakta ve bu parçacıkların etrafinda iyonik bir bulut oluşturmaktadırlar. İyonlarla çevrelenmiş ikinci faz parçacıklar (kollodial parçacıklar) bu sayede katoda doğru sürüklenmektedirler. Daha sonra katot yüzeyine önce zayıf bir şekilde adsorblanan parçacıklar diğer bir yandan elektrik yüklerini boşaltan metal iyonları arasında kalarak katot yüzeyinde büyüyen metal tabakaları arasında kapana kısılmakta ve böylece kademe kademe birlikte depolanma olayı gerçekleşmektedir.

Şekil 4'de saf nikel, Ni-B alaşım ve $\mathrm{Ni-B} / \mathrm{TiB}_{2}$ nanokompozit kaplamaların dönüşümlü voltametri (CV) grafikleri her kaplama çeşidini temsil eden eğrilere farklı renkler verilerek sunulmuştur. CV tekniğinde potansiyel zamanla doğrusal olarak değiştirilir. Zamanla potansiyelin birbirleri arasındaki değişim hızı tarama hızı olarak isimlendirilir [40]. Bu grafiklerden elektrolitin indirgenme ve yükseltgenme potansiyelleri akımın yükselmesi ile anlaşılmakta ve banyoya eklenen bileşenlerin bu değerleri nasıl etkilediği hakkında önemli bilgiler elde edilmektedir. Elektrokimyasal kaplamada akım ve potansiyel en önemli ve temel üretim parametrelerindendir. Şekil 4'den görüleceği üzere katodik yönde, yani 1,2 V'tan-1,2 V'a (sağdan sola doğru) grafik incelendiğinde $1,2 \mathrm{~V}$ ile $0,4 \mathrm{~V}$ arasında ortaya çıkan pikler gaz çıkışına işaret etmektedir. Yaklaşık olarak $0 \mathrm{~V}$ değerinden sonra akım değeri de sıfır amper (A) olarak ilerlemekte ve $-0,7 \mathrm{~V}$ değeri civarlarına kadar düz bir eğri şeklinde devam etmektedir. $\mathrm{Bu}$ aralıkta elektrokimyasal banyoda herhangi reaksiyon olmadığı gözlenmektedir. 3 elektrokimyasal banyoda da $-0,83 \mathrm{~V}$ civarlarına gelindiğinde ani akım artışıyla birlikte nikel metalinin depolanmaya başladığ 1 anlaşılmaktadır. Yani banyoya bor kaynağı TMAB ve takviye parçacık $\mathrm{TiB}_{2}$ eklenmesi depolanma başlangıç potansiyelini çok fazla etkilememiştir. Fakat $\mathrm{TiB}_{2}$ parçacıklarının elektrolite eklenmesinin akım yoğunluğunda bir azalmaya sebep olduğu grafikten görülmektedir. $\mathrm{Bu}$ durumun takviye parçacıkların elektrolit iletkenliğinde bir miktar azalmaya sebep olmasından dolayı olduğu öne sürülebilir. $\mathrm{TiB}_{2}$ her ne kadar elektriksel olarak 
iletken bir seramik olmasına rağmen, saf nikel ve Ni-B alaşımlarının depolandığı $\mathrm{TiB}_{2}$ parçacıklarının ilave edilmediği banyolara kıyasla elektrolitin elektrik iletkenliğinde azalma olması muhtemeldir. TMAB ilavesi ise akım yoğunluğu üzerinde önemsenmeyecek derecede çok küçük bir artış etkisi göstermiştir. Anodik yön, yani eksi potansiyelden artı potansiyele doğru tarama yapıldığında depolanan metal geri elektrolit içine çözünmekte ve bu esnada pik şeklinde tepe veya tepeler ortaya çıkmaktadır. Şekilde verilen grafik incelendiğinde saf nikele ait $\mathrm{CV}$ eğrisinde $-0,1 \mathrm{~V}$ ve $0,05 \mathrm{~V}$ civarlarında 2 adet çözünme piki olduğu görülmektedir. Elektrolite TMAB ilavesi çözünme pikinin yüksekliğinin artmasına pozitif tarafa kaymasına sebep olmuştur. Ni-B alaşım üretilen banyoda çözünme piki $0,3 \quad \mathrm{~V}$ civarında görülmektedir. Daha sonra nanokompozit kaplama üretilen $\mathrm{TiB}_{2}$ ilave edilmiş banyo için çözünme piki, indirgenme tarafinda olduğu gibi, yüksekliği saf nikele göre daha da azalmış ve bir miktar pozitif tarafa kaymıştır.

Şekil 5'te paslanmaz çelik altlık, saf nikel, Ni-B alaşım ve $\mathrm{Ni}-\mathrm{B} / \mathrm{TiB}_{2}$ nanokompozit kaplamaların

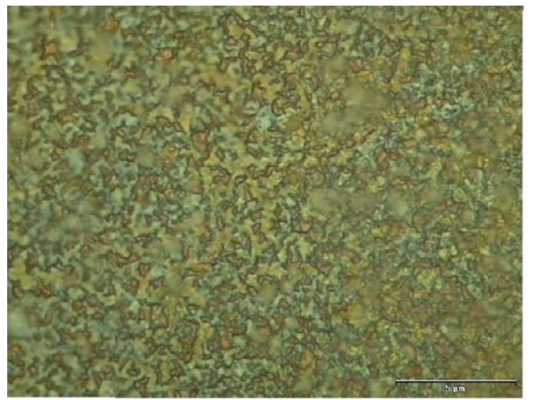

Saf nikel mikro sertlik değerleri verilmiştir. Mikro sertlik ölçümleri paslanmaz çelik için $203 \mathrm{Hv}$, saf nikel için $290 \mathrm{Hv}$, Ni-B alaşım için $400 \mathrm{Hv}$ ve $\mathrm{Ni}-\mathrm{B} / \mathrm{TiB}_{2}$ nanokompozit kaplama için ise $700 \mathrm{Hv}$ olarak elde edilmiştir. Elde edilen sonuçlar göstermektedir ki, banyoya eklenen bileșenler mikro sertliğin artmasına sebep olmuştur. Banyoya TMAB eklenmesi neticesinde nikel ana yapısına dahil olan bor atomları sertlik değerinin yaklaşık olarak \%38 oranında artmasına sebep olmuştur. Sheu ve arkadaşları [34] elektrodepolanmış Ni-B alaşımları için sertleşme mekanizmasını incelemişler ve sertlik artı̧̧ının katı çözelti sertleşmesi ve tane boyu küçülmesinden kaynaklandığını ifade etmişlerdir. Banyoya titanyum diborür parçacıklarının ilavesi ile birlikte ise sertlik değeri saf nikele göre yaklaşık olarak \%140 oranında, Ni-B alaşım kaplamaya göre ise yine yaklaşık olarak \%75 oranında artışa sebep olduğu görülmektedir. Parçacık takviyeli kompozitlerde sertlikte artışın temel nedenlerinden biri bu parçacıkların ana yapı içerisinde çizgi kusurları (dislokasyon) hareketlerini engellemesidir. Bu durum genel olarak dayanımda ve sertlikte artışa sebep olmaktadır [6].

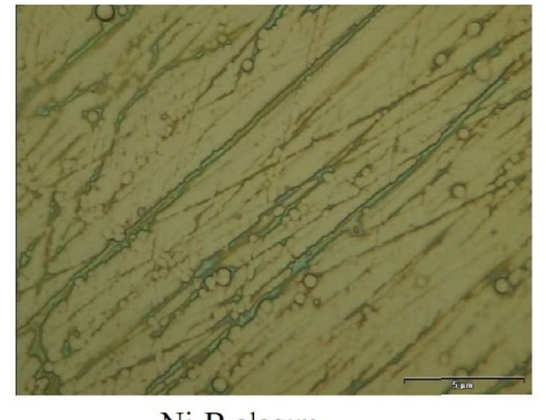

Ni-B alaşım

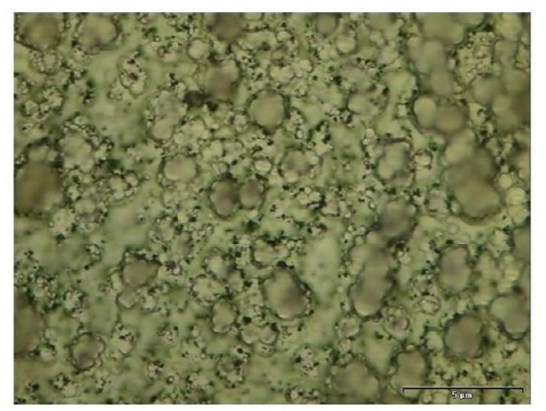

$\mathrm{Ni}-\mathrm{B} / \mathrm{TiB}_{2}$ nanokompozit 


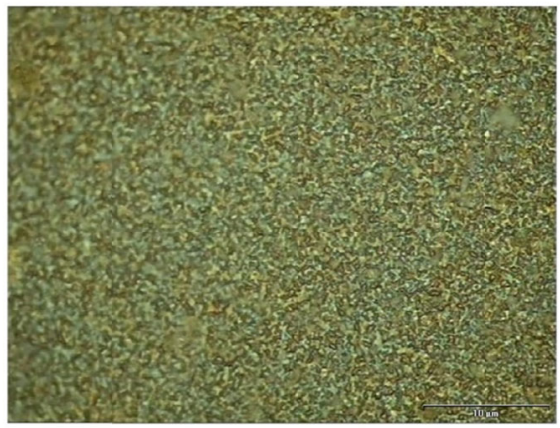

Saf nikel

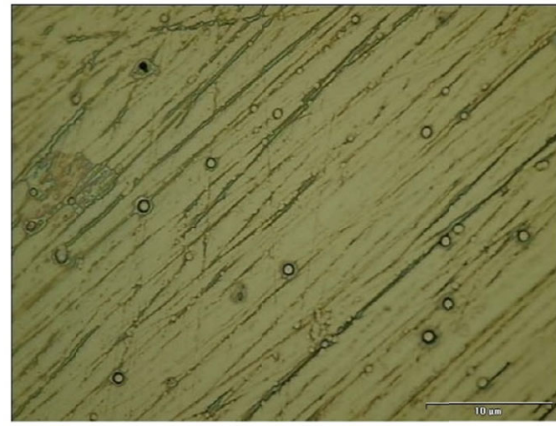

$\mathrm{Ni}-\mathrm{B}$ alașım

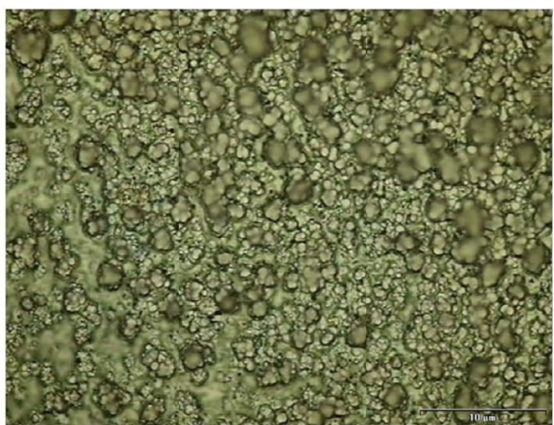

$\mathrm{Ni}-\mathrm{B} / \mathrm{TiB}$, nanokompozit

Şekil 3. Saf nikel, Ni-B alaşım ve Ni-B/TiB ${ }_{2}$ nanokompozit kaplamaların optik mikroskop resimleri (üstte $1000 x$, altta $500 x$ büyütme)

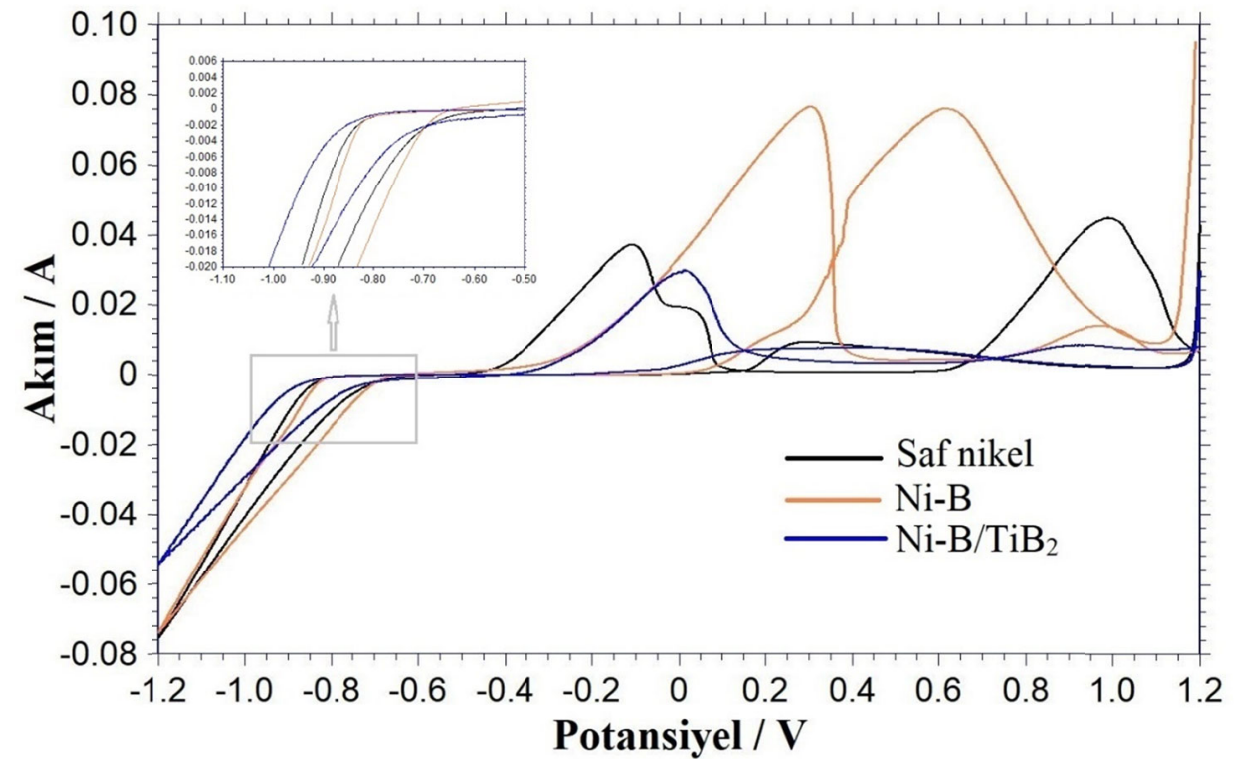

Şekil 4. Saf nikel, Ni-B alaşım ve Ni-B/TiB 2 nanokompozit kaplamaların dönüşümlü voltametri $(\mathrm{CV})$ grafikleri 


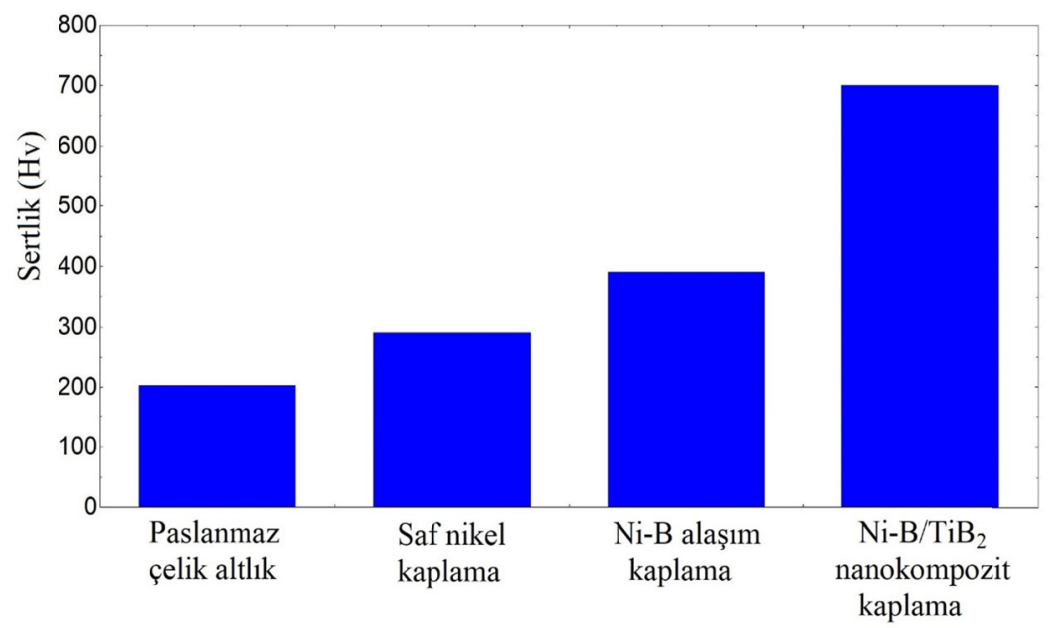

Şekil 5. Paslanmaz çelik altlık, saf nikel, Ni-B alaşım ve Ni-B/TiB ${ }_{2}$ nanokompozit kaplamaların mikro sertlik değerleri

Şekil 6'da Saf nikel, Ni-B alaşım ve Ni-B/TiB 2 nanokompozit kaplamaların açık devre potansiyel (OCP) değerleri verilmiştir. İyonik bir çözeltiden ölçülen potansiyel değeri katodik ve anodik reaksiyonların denge potansiyelidir ve bu ortam korozif bir ortam ise ölçtüğümüz bu voltajı korozyon potansiyeli olarak kabul edebiliriz. Açık devre potansiyeli grafiklerinde pozitif tarafa daha yakın olan eğrilerin numunelerinin korozyon dayanımlarının daha yüksek olduğu bilinmektedir
[35,41]. Şekil 6 incelendiğinde saf nikel üretim banyosuna TMAB eklenerek üretilen $\mathrm{Ni-B}$ alaşımının korozyon performansının düşüş gösterdiği görülmektedir. Ana yapıya bor atomlarının dahil olması korozyon dayanımını kötü etkilemiştir. Bu duruma borun kristal yapıda iç gerginliklere sebep olması neticesinde ortaya çıkan mikro ve makro çatlakların sebep olduğu söylenebilir.

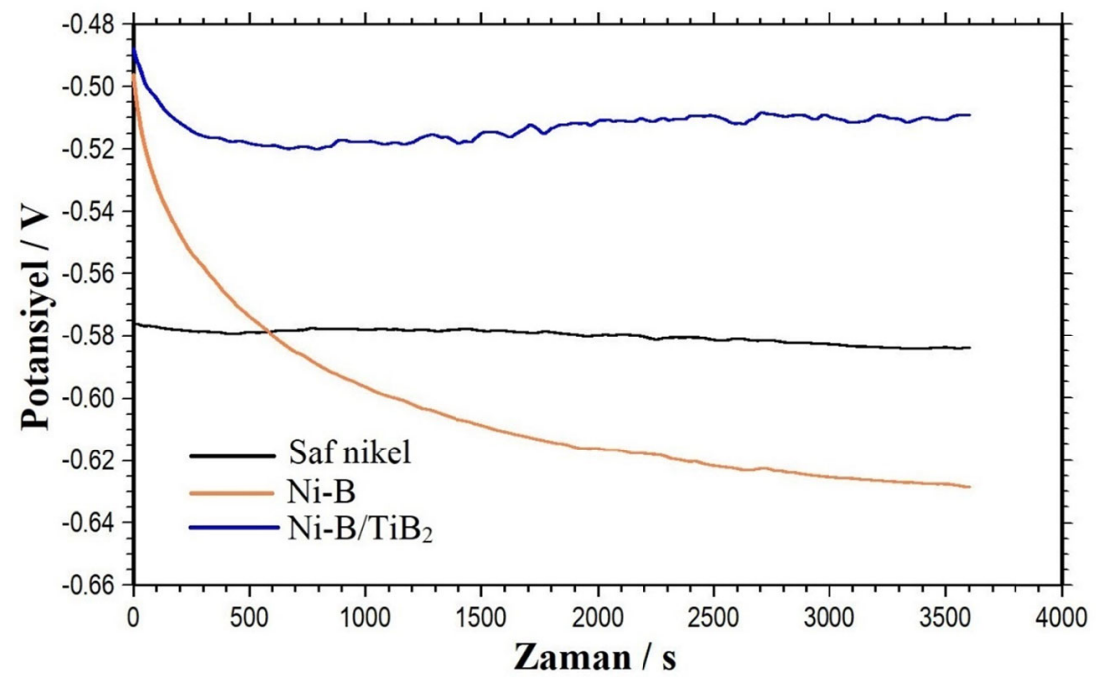

Şekil 6. Saf nikel, Ni-B alaşım ve $\mathrm{Ni}-\mathrm{B} / \mathrm{TiB}_{2}$ nanokompozit kaplamaların açık devre potansiyel (OCP) değerleri 


\section{Elektrodepolanmış Nanokompozit Kaplamalarda Elektrolit Bileşenlerinin Etkisi}

Şekil 7'de bu kırık ve çatlaklı durumun yüzey görüntüsü verilmiştir. Banyoya eklenen $\mathrm{TiB}_{2}$ parçacıklarının kaplamaya dahil olması ile birlikte korozyon dayanımımın da artış gösterdiği Şekil 6'da nanokompozit kaplamaya ait OCP eğrisinin daha pozitif tarafa kaymasından anlaşılmaktadır. Ni-B alaşım ana yapıya dahil olan $\mathrm{TiB}_{2}$ parçacıkları hem kaplamanın daha tok olmasina hem de korozyona daha dayanıklı olmasına neden olmuştur. Korozyon dayanımındaki bu gelişme, kompozit kaplamanın yüzeyi üzerindeki çatlakların, boşlukların ve mikron boyutunda deliklerin $\mathrm{TiB}_{2}$ parçacıkları tarafından doldurularak fiziksel bir bariyer görevi görmesinden dolayı olduğu öne sürülebilir [42]. Korozyon dayanımının artmasiyla ilgili diğer bir görüş ise elektrokimyasal kaplama işlemi esnasında tanecik sınırlarında iyi bir şekilde dağılım gösteren takviye parçacıklar kaplamadaki kusurları azaltmaktadır ve kaplamayı daha kompakt ve daha az geçirgen hale getirmektedir. $\mathrm{Bu}$ durum ise korozyon dayanımında artışa sebep olmaktadir [43].

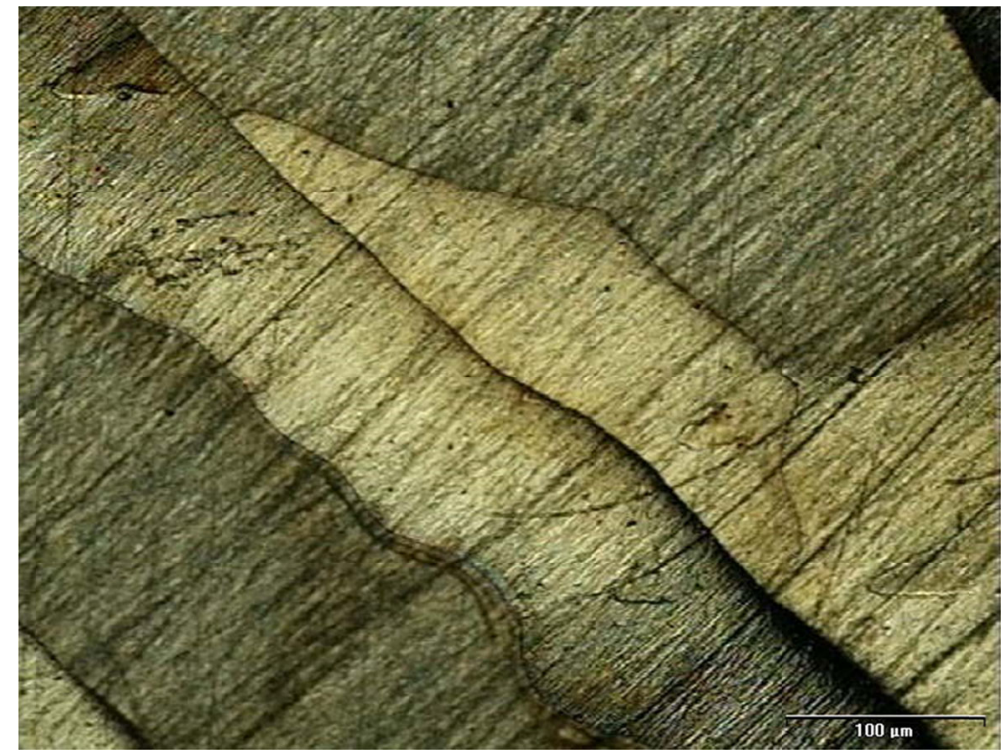

Şekil 7. Ni-B alaşım kaplamanın kırık ve çatlaklardan oluşan yüzey morfolojisi

\section{SONUÇLAR}

Bu çalıșmada, saf nikel, Ni-B alaşım ve $\mathrm{Ni}-\mathrm{B} / \mathrm{TiB}_{2}$ nanokompozit kaplamalar elektrokimyasal depolama metodu ile üretilmiştir. Alaşım kaplama ve nanokompozit kaplama elde edebilmek için banyoya eklenen her bir bileşenin kaplama özelliklerine etkileri çeşitli analiz teknikleri ile incelenmiştir. Elde edilen kronopotansiyometri grafiklerine göre saf nikel ve nanokompozit kaplamalardaki potansiyel değișiminin alaşım kaplama banyosuna göre daha yatay ve stabil bir seyir izlediği söylenebilir. CV diyagramlarına göre ise nanokompozit kaplamanın elde edildiği banyoda depolanma akımı artış hızının diğer banyolara göre daha düşük olduğu görülmektedir. Genel olarak elde edilen kaplamaların pürüzsüz olduğu görülürken, kendi içinde karşılaştırıldıklarında bor takviyesi yüzey morfolojisinin daha pürüzsüz olmasına, $\mathrm{TiB}_{2}$ takviyesi ise daha pürüzlü olmasına neden olmuştur. Hem bor takviyesi hem de $\mathrm{TiB}_{2}$ takviyesi saf nikele göre ciddi derecede mikro sertlik artışına sebep olmuştur. Korozyon performansı açısından bor olumsuz bir etkiye sahipken $\mathrm{TiB}_{2}$ parçacıklarının olumlu bir etkiye sahip olduğu söylenebilir. Saf nikel anayapısı üzerinde bor ve $\mathrm{TiB}_{2}$ takviyesi ile ilgili elde edilebilecek 
gelişmelerin daha detaylı irdelenmesi adına daha fazla deney ve analiz yapılması gerektiği görülmektedir. $\mathrm{Bu}$ kaplamalarla ilgili bundan sonraki çalışmalarda bu eksiklikler göz önüne alınarak daha fazla bilimsel çalışma yapılabilir.

\section{KAYNAKLAR}

1. Tozar, A., Karahan, İ.H., 2020. Effect of Octylphenyl Ether Group Nonionic Surfactant on the Electrodepositon of the Hexagonal Boron Nitride Reinforced Ni-B Matrix Composite Coatings, Surface \& Coatings Technology, 381, 125131.

2. Baosong, L., Xiao, L., Yuxing, H., Wenzhe, X., Weiwei, Z., 2018. Influence of Alumina Nanoparticles on Microstructure and Properties of Ni-B Composite Coating, Journals of Alloys and Compounds, 762, 133-142.

3. Dandan, L., Baosong, L., Shengsong, D., Weiwei, Z., 2019. Synthesis of a Novel NiB/YSZ Metal-ceramic Composite Coating Via Singlestep Electrodeposition at Different Current Density, Ceramics International, 45, 24884-24893.

4. García-Aguirre, C.A., Domínguez-Ríos, C., Torres-Sánchez, R., Román-Aguirre, M., Holguín-Momaca, J.T., Aguilar-Elguézabal, A., 2015. Microstructure and Transmission Electron Microscopy Characterization of Electroless Ni-B Thin Films Deposited on MWCNTs, Surface \& Coatings Technology, 282, 107-114.

5. Shakoor, R.A., Kahraman, R., Waware, U., Wang, Y., Gao, W., 2014. Properties of Electrodeposited Ni-B- $\mathrm{Al}_{2} \mathrm{O}_{3}$ Composite Coatings, Materials \& Design, 64, 127-135.

6. Shakoor, R.A., Kahraman, R., Waware, U.S., Wang, Y., Gao, W., 2014. Synthesis and Properties of Electrodeposited Ni-B- $\mathrm{CeO}_{2}$ Composite Coatings Materials \& Design, 59, 421-429.

7. Kanani, N., 2004. Electroplating: Basic Principles, Processes and Practice, Elsevier Advanced Technology, Oxford, U.K.

8. Srivastava, M., William, G.V., Rajam, K.S., 2007. Electrochemical Deposition and Tribological Behaviour of Ni and Ni-Co Metal
Matrix Composites with $\mathrm{SiC}$ Nano-particles. Applied Surface Science, 253, 3814.

9. Singh, V.B., Singh, D.K., 2014. An Overview on the Preparation, Characterization and Properties of Electrodeposited-Metal Matrix Nanocomposites, Nano sci Technol 1 (3), 1-20.

10. Koch, C.C., 2007. Structural Nanocrystalline Materials: An Overwiew, J. Mater. Sci. 42, 1403.

11. Shakoor, R.A., Kahraman, R., Waware, U.S., Wang, Y., Gao, W., 2014. Synthesis and Properties of Electrodeposited Ni-B-Zn Ternary Alloy Coatings, Int. J. Electrochem. Sci., 9, 5520.

12. Ünal, E., Yaşar, A., Karahan, İ.H., 2019. A Review of Electrodeposited Composite Coatings with Ni-B Alloy Matrix, Maretials Research Express, 6, 092004.

13. Ünal, E., Karahan, İ.H., 2018. Production and Characterization of Electrodeposited Ni-B/hBN Composite Coatings, Surface \& Coatings Technology, 333, 125-137.

14. Ünal, E., Karahan, İ.H., 2018. Investigation of Effect of the Bath Components on Coating Properties in Electrodeposition of Ni, Ni-B and Ni-B/hBN Coatings, Sakarya University Journal of Science, 22 (2), 663-672.

15. Ünal, E., Karahan, İ.H., 2018. Effects of Ultrasonic Agitation Prior to Deposition and Additives in the Bath on Electrodeposited Ni$\mathrm{B} / \mathrm{hBN}$ Composite Coatings, Journal of Alloys and Compounds, 763, 329-341.

16. Tozar, A., Karahan, İ.H., 2019. Investigation of the Mechanical Properties of Ni-B/hBN Composite Coatings Electrodeposited in Presence of CTAB as the Surfactant, Materials Research Express, Volume 6, Number 12.

17. Baosong, L., Weiwei, Z., 2020. Facile Synthesis and Electrochemical Properties of a Novel Ni-B/TiC Composite Coating Via Ultrasonic-assisted Electrodeposition, Ultrasonics-Sonochemistry 61, 104837.

18. Hosseini, M.G., Ahmadiyeh, S., Rasooli, A., 2019. Pulse Plating of Ni-B/WC Nanocomposite Coating and Study of its Corrosion and Wear Resistance, Materials Science and Technology, 35(10), 1248-1256.

19. Ahmadiyeh, S., Rasooli, A., Hosseini, M.G., 2019. Ni-B/SiC Nanocomposite Coating 


\section{Elektrodepolanmış Nanokompozit Kaplamalarda Elektrolit Bileşenlerinin Etkisi}

Obtained by Pulse Plating and Evaluation of its Electrochemistry and Mechanical Properties, Surface Engineering, 35(10), 861-872.

20. Li, B.S., Huan, Y.X., Luo, H., Zhang, W.W., 2019. Electrodeposition and Properties of $\mathrm{Ni}-\mathrm{B} / \mathrm{SiC}$ Nanocomposite Coatings, Surface Engineering, 35(2), 109-119.

21. Mehr, M.S., Akbari, A., Damerchi, E., 2019. Electrodeposited Ni-B/SiC Micro- and Nano-composite Coatings: A Comparative Study, Journal of Alloys and Compounds, 782, 477-487.

22. Krishnaveni, K., Narayanan, T.S.N.S., Seshadri, S.K., 2008. Electrodeposited $\mathrm{Ni}-\mathrm{B}-\mathrm{Si}_{3} \mathrm{~N}_{4}$ Composite Coating: Preparation and Evaluation of its Characteristic Properties, J. of Alloys and Compounds, 466, 412-420.

23. Monteiro, O.R., Murugesan, S., Khabashesku, V., 2015. Electroplated Ni-B Films and Ni-B Metal Matrix Diamond Nanocomposite Coatings, Surface \& Coatings Technology, 272, 291-297.

24. Ogihara, H., Safuan, M., Saji, T., 2012. Effect of Electrodeposition Conditions on Hardness of $\mathrm{Ni}-\mathrm{B} /$ diamond Composite Films, Surface \& Coatings Technology, 212, 180-184.

25. Shakoor, R.A., Waware, U.S., Ali, K., Kahraman, R., Popelka, A., Yusuf, M.M., Hasan, A., 2017. Novel Electrodeposited $\mathrm{Ni}-\mathrm{B} / \mathrm{Y}_{2} \mathrm{O}_{3}$ Composite Coatings with Improved Properties, Coatings, 7, 161.

26. Waware, S., Wasekar, N.P., 2017. Manufacture and Properties of Ni-B-Fe $\mathrm{O}_{3}$ Composite NanoCoatings by Electrodeposition, Journal of Material Sciences \& Engineering, 6, 6.

27. Waware, U.S., Hamoudaa, A.M.S., Wasekar, N.P., 2018. Mechanical Properties, Thermal Stability and Corrosion Behavior of Electrodeposited Ni-B/AlN Nanocomposite Coating, Surface \& Coatings Technology, 337, 335-341.

28. Waware, U.S., Hamouda, A.M.S., Bajaj, B., Borkar, T., Pradhan, A.K., 2018. Synthesis and Characterization of Electrodeposited Ni-B- $\mathrm{Tl}_{2} \mathrm{O}_{3}$ Composite Coatings, Journal of Alloys and Compounds, 769, 353-359.

29. Ett, G., Pessine, E.J., 1999. Pulse Current Plating of $\mathrm{TiB}_{2}$ in Molten Fluoride, Electrochimica Acta, 44, 2859-2870.
30. Gyawali, G., Cho, S.H., Lee, S.W., 2013. Electrodeposition and Characterization of $\mathrm{Ni}^{-\mathrm{TiB}_{2}}$ Composite Coatings, Metals and Materials International, 19(1), 113-118.

31. Gyawali, G., Tripathi, K., Joshi, B., Lee, S.W., 2017. Mechanical and Tribological Properties of Ni-W-TiB 2 Composite Coatings, Journal of Alloys and Compounds, 721, 757-763.

32. Xiaozhen, L., Yifan, L., Lingling, S., Xiaowen, S., 2010. Preparation and Performance of Electrodeposited $\mathrm{Ni}-\mathrm{TiB}_{2}-\mathrm{Sm}_{2} \mathrm{O}_{3}$ Composite Coatings, Journal of Rare Earths, 28, 97.

33. Xiaozhen, L., Xin, L., Aibing, Y., Weijue, H., 2009. Preparation and Tribological Performance of Electrodeposited $\mathrm{Ni}-\mathrm{TiB}_{2}-\mathrm{Dy}_{2} \mathrm{O}_{3}$ Composite Coatings, Journal of Rare Earths, 27(3), 480.

34. Sheu, H.H., Tzeng, Y.C., Syu, J.H., 2019. Study of the Strengthening Mechanism of Electrodeposited Ni-B Thin Films with Ultra-low Boron Content, Materials Letters, 238, 275-277.

35. Tozar, A., 2012. Düşük Karbonlu Çeliğin Çevreci ZnNi/Polianilin İletken Polimer ile Kaplanması ve Kaplanan Çeliğin Korozyon Davranışının İncelenmesi, Mustafa Kemal Üniversitesi, Fen Bilimleri Enstitüsü. Yüksek Lisans Lisans Tezi, Hatay.

36. Lee, K.H., Chang, D., Kwon, S.C., 2005. Properties of Electrodeposited Nanocrystalline Ni-B Alloy Films, Electrochimica Acta, 50, 4538-4543.

37. Lekka, M., Offoiach, R., Lanzutti, A., Mughal, M.Z., Sebastiani, M., Bemporad, E., Fedrizzi, L., 2018. Ni-B Electrodeposits with Low B Content: Effect of DMAB Concentration on the Internal Stresses and the Electrochemical Behaviour, Surface \& Coatings Technology, 344, 190-196.

38. Matsui, I., Omura, N., Yamamoto, T., Takigawa, Y., 2018. Electrodeposition with Intermittent Addition of Trimethylamine Borane to Produce Ductile Bulk Nanocrystalline Ni-B Alloys, Surface \& Coatings Technology, 337, 411-417.

39. Guglielmi, N., 1972. Kinetics of the Deposition of Inert Particles from Electrolytic Baths, Journal of The Electrochemical Society, 119 (8), 1009-1012. 
40. Öztekin, K., 2014. Çinko Kaplanmış Karbon Çeliğinin Na-okzalat ve Na-tartarat Ortamlarında Polianilin ve Poli-o-anisidin ile Kaplanarak Korozyon Direncinin Geliştirilmesi, Mustafa Kemal Üniversitesi, Fen Bilimleri Enstitüsü. Yüksek Lisans Lisans Tezi, Hatay.

41. Tozar, A., Karahan, İ.H., 2014. Structural and Corrosion Protection Properties of Electrochemically Deposited Nano-sized Zn-Ni Alloy Coatings, Appl. Surf. Sci. 318, 15-23.

42. Kasturibai, S., Kalaignan, G.P., 2014, Characterizations of Electrodeposited $\mathrm{Ni}-\mathrm{CeO}_{2}$ Nanocomposite Coatings, Materials Chemistry and Physics, 147, 1042-1048.

43. Wang, Y., Wang, S., Shu, X., Gao, W., Lu, W., Yan, B., 2014. Preparation and Property of SolEnhanced Ni-B-TiO ${ }_{2} \quad$ Nano-composite Coatings, J. of Alloys and Compounds, 617, 472-478. 
